\title{
Nanocapsulated Rift Valley Fever Vaccine Candidates and Relative Immunological and Histopathological Reactivity in Out Bred Swiss Mice
}

Noha Emad El-Din Abd el-Razek, Sahar A. Shoman and Aly Fahmy Mohamed*

The Holding Company for Biological Products, Vaccines and Drugs (VACSERA), 51 Wezaret El-Zeraa street, Dokky GIZA -Egypt

\begin{abstract}
The present work aimed to compare the potentials of Alum and CAP as adjuvants and related immune response to RVFV vaccines candidates inactivated using different inactivants namely, Formalin, Beta-Propiolactone (BPL) and Ascorbic acid (AA). Potency (ED50) of inactivated vaccines was arranged in the order of BPL (0.006), AA (0.0024), and formalin (0.011) respectively. Data recorded revealed that BPL inactivated showed a fast inactivating efficacy and inactivation time was arranged as BPL ( 2 hrs) followed by formalin $(6 \mathrm{hrs})$ and AA (within $24 \mathrm{hrs})$. BPL - CAP adjuvanted RVFV vaccine showed a higher and long durative antibody level than that detected post immunization with the other RFVF vaccine formulations either alum or CAP adjuvanted vaccines. Limited histopathological changes detected post CAP adjuvanted vaccine compared with that detected post Alum adjuvanted one was detected.
\end{abstract}

Keywords: RVFV vaccine; Nanoparticle CAP adjuvant; Alum; Adjuvant activity; Adjuvant side effects

\section{Introduction}

Rift Valley fever (RVF) is an arthropod-borne, multi-species zoonotic viral disease of livestock whose causative agent was first isolated in the 1930s. It had been exclusively confined to the African continent, but RVF spread to the Middle East in 2000. The occurrence of the disease is usually reliant on the presence of susceptible animals, a build-up of the mosquito vector population (usually associated with heavy rains) and the presence of the virus. Vaccination has been used for the control of RVF in southern and East Africa. Two types of vaccines have been described: Formalin-inactivated RVF vaccines have been used to immunize animals, laboratory workers, veterinarians and other people at high risk of exposure to RVFV. The cost of the vaccine production, the requirement for multiple inoculations required for protective immune response limit its use just for veterinary purposes [1]. Outbreaks of RVF in animals can be prevented by a sustained programme of animal vaccination. Both modified live attenuated vaccine (Smithburn and MP12 strains) and inactivated (M/S/258 and $\mathrm{ZH}-501$ ) virus vaccines have been developed for veterinary use. Only one dose of the live vaccine is required to provide long-term immunity but the vaccine that is currently in use may result in spontaneous abortion if given to pregnant animals. The inactivated virus vaccine does not have this side effect, but multiple doses are required in order to provide protection which may prove problematic in endemic areas [2-4].

An effective vaccine usually requires an adjuvant to increase the immune response. More than 100 compounds or formulations show some degree of adjuvant properties [5]. At the beginning of the 20th century, researchers experimented with a wide variety of organic and inorganic compounds including aluminium salts, mineral oil, and killed mycobacteria to improve the immunogenicity of vaccines [3]. The most common adjuvants approved for use in currently licensed human vaccines are the aluminium based adjuvants [6].

Adjuvants have been necessary to improve vaccine efficacy in order to afford protection against infections. A key reason for this is that both attenuated virus preparations and, particularly, recombinant proteins are often poorly antigenic. In the past decade, several adjuvants have been evaluated in clinical trials. Calcium phosphate (CAP), MF59, aluminium (alum) compounds, and virosomes have been approved for human use in several European countries [7]. In the United States, alum compounds are the most extensively used adjuvants in licensed vaccines for humans. Although they effectively enhance immune responses, there are several disadvantages associated with their use $[6,8,9]$. The disadvantages of alum-based adjuvants include the severity of local tissue irritation, the longer duration of the inflammatory reaction at the injection site, strong Th 2 responses, minimal induction of cell-mediated immunity, and a propensity to elicit undesirable immunoglobulin $\mathrm{E}$ (IgE) responses [10-12]. Alum compounds have also been shown to increase the levels of potential undesirable homocytotropic antibodies in animal species [13]. Furthermore, alum-based vaccines are frequently ineffective for the induction of antiviral immunity [4]. For these reasons, new adjuvants are being developed to enhance the immunity against weak antigens. New-generation adjuvants are designed to induce minimal side effects, enhance the duration of the immune response, and concurrently stimulate humoral responses. Furthermore, an ideal adjuvant would be biodegradable, economical, and simple to manufacture. In addition, it would have the potential to selectively trigger a defined class of immune response. Nanomaterials have unique physicochemical properties, such as ultra small size, large surface area to mass ratio, and high reactivity, which are different from bulk materials of the same composition. These properties can be used to overcome some of the limitations found in traditional vaccines [14]. Replacement of aluminium salts with calcium phosphate has long been described [15]. Efforts with calcium adjuvants have continued, and work with calcium phosphate nanoparticles has had some preclinical success [16]. CAP based viral vaccines induce a higher IgG2a response and a lower IgE response relative to the responses induced by alum

*Corresponding author: Aly Fahmy Mohamed, The Holding Company for Biological Products, Vaccines and Drugs (VACSERA), 51 Wezaret El-Zeraa street, Dokky GIZA -Egypt, Tel: 202- 37611111 Ext. 3398; Fax: 202- 33483187; E-mail: alyfahmy2002@yahoo.com

Received December 10, 2010; Accepted March 10, 2011; Published March 15, 2011

Citation: Abd el-Razek NEE, Shoman SA, Mohamed AF (2011) Nanocapsulated Rift Valley Fever Vaccine Candidates and Relative Immunological and Histopathological Reactivity in Out Bred Swiss Mice. J Vaccines Vaccin 2:115. doi:10.4172/2157-7560.1000115

Copyright: (c) 2011 Abd el-Razek NEE, et al. This is an open-access article distributed under the terms of the Creative Commons Attribution License, which permits unrestricted use, distribution, and reproduction in any medium, provided the original author and source are credited. 
Citation: Abd el-Razek NEE, Shoman SA, Mohamed AF (2011) Nanocapsulated Rift Valley Fever Vaccine Candidates and Relative Immunological and Histopathological Reactivity in Out Bred Swiss Mice. J Vaccines Vaccin 2:115. doi:10.4172/2157-7560.1000115

Page 2 of 7

[17]. So the present work aimed to improve the nanocapsulated RVFV vaccine using CAP nano particles through use different inactivants other than the currently used Formalin and BPL concerning virus inactivation efficacy, prepared vaccine immunogenicity and potential in the mean time demonstrate the histopathological changes developed post administration of both Alum and cap capsulated RVFV vaccine.

\section{Materials and Methods}

\section{RVFV Strain}

RVFV; Pan Tropic - Menya Strain (Menya/Sheep/258) was kindly provided by Dr. Aly Fahmy, G.M. of Applied research sector The Holding Company for Biological products, Vaccines and Drugs (VACSERA), Giza, Egypt. RVFV was of an infectivity titre in the order of $7.5 \log _{(10)} / \mathrm{ml}$. Virus seed was propagated intraperitoneally in mice.

\section{Maintenance of cell line and seed stock preparation}

Chicken Embryo Related cells (CER), kindly provided by cell culture department, virology sector. Cell line was maintained [18-19]. Virus seed stock was prepared according to [20], where growth medium was removed from the CER cell precultured flasks; the monolayer was washed with sterile PBS, pH 7.2. $5 \mathrm{ml}$ of 100 TCID50 of RVFV was dispensed to each flask. Bottles were shacked at 15 min interval for assurance of well virus distribution then $100 \mathrm{ml}$ of maintenance media were dispensed to each flask. Inoculated flasks were daily microscopically examined for 7 days for detection of cellular changes and development of cytopathic effect (CPE). Flasks developed CPE were freezed and thawed three successive times for virus extraction [21].

\section{Inactivation of RVFV using chemical inactivants}

Ascorbic acid (AA), copper sulphate, Beta propiolactone (BPL) and Formalin were purchased from (Sigma - Aldrich, USA). AA Stock solutions $(0.1 \mathrm{M}$ of copper sulphate and $0.5 \mathrm{M}$ of ascorbic acid) were prepared in sterile distilled water and sterilized by membrane filtration (Millipore-USA). AA was prepared as [22]; $0.88 \mathrm{gm}$ was dissolved in 10 $\mathrm{ml}$ of maintenance medium. $\mathrm{PH}$ was adjusted as 5 using $0.1 \mathrm{~N} \mathrm{NaOH}[22-$ 23]. The stock solutions were added to the virus suspension to obtain a final concentration of $5 \mathrm{mg} / \mathrm{ml}$ of copper sulphate and $1.5 \mathrm{mg} / \mathrm{ml} \mathrm{AA}$. The treated virus was incubated at $37^{\circ} \mathrm{C}$ incubators (Jouan, France) with continuous stirring. Second aliquot of RVFV was inactivated using BPL prepared as $0.0035 \mathrm{M}$ [18-19], Cold distilled water diluted BPL was stepwise dispensed to virus aliquot with continuous stirring. Also, RVFV was inactivated using $0.2 \%$ formalin [20], formalin was diluted in HBSS pH 7.2 as $40 \%$ final concentration and added to the virus suspension to obtain at final concentration $0.2 \%$.

\section{Determination of Inactivation kinetics of RVFV}

Inactivation kinetics relatively to time post inactivants treatment was determined [19-24] where $1 \mathrm{ml}$ of chemically treated virus was collected at time interval according to the inactivants used. Virus samples were 10 fold serially diluted 101-108 in MEM-E Prepared dilutions were dispensed onto precultured CER cell line in 96 well plates (TPP-Swiss). Infected cultured plates were incubated in $\mathrm{CO} 2$ incubator (Jouan-France). The same virus dilutions were transferred in an ice water bath to the animal house and intraperitoneally inoculated in 21days old Swiss mice (male weaning mice, $14-16 \mathrm{gm}$ ), $10 /$ cage. Tissue culture plates and mice groups were daily examined for detection of Cytopathic effect (CPE) and signs of illness / mortality. $50 \%$ end point induced (CPE/mortality) was determined [25]. In case of formalin treatment, when residual live virus could not be detected Residual formalin was neutralized using $35 \%$ Na-bisulphite as a $0.0289 \%$ final concentration [21].

\section{Toxicity of chemical inactivants}

Toxicity of ascorbic acid ( $1.5 \mathrm{mg} / \mathrm{ml}), 0.2 \%$ formaldehyde solution neutralized with Nabisulphite and $0.0035 \mathrm{M}$ Beta-propiolactone was determined [26].

\section{Animals}

Approval for the use of animals for analgesic experiments had been obtained from the Ethical Committee of the Faculty of Pharmacy, Cairo University, Egypt. Swiss mice of either sex obtained from the Animal House unit of the Department of Pharmacology \& Toxicology, Faculty of Pharmacy, Cairo University, Egypt were used. The animals maintained under standard laboratory conditions ( $12 \mathrm{~h}$ light and dark cycles) had free access to standard chow and water.

\section{Acute toxicity}

Acute toxicity was performed according to the OECD-423 guidelines [27]. Intraperitoneal acute toxicity was studied in mice. The animals had free access to feed and drinking water. Swiss mice (18-20 $\mathrm{gm}$ ) of either sex were randomly allocated into groups of 10 animals per group. They were administered intraperitoneally aqueous extract of test materials. General symptoms of toxicity and mortality were observed for $24 \mathrm{~h}$, after which the animals were left for further 7 days for delayed toxicity.

\section{Determinations of RVF challenge virus titre using mice assay}

Infectivity titre of stock of RVF virus used for challenge of immunized mice was determined [21]; liver harvest virus seed stock was 10 fold serially diluted in MEM-E supplemented with 2\% FCS. Each mice group (10 each) received $0.1 \mathrm{ml} /$ mouse intraperitoneal route of administration. Mice groups were observed for 7 days post inoculation for detection of signs of illness and mortality. RVF virus end point induced $50 \%$ mice mortality was determined [25].

\section{Determination of the inactivated RVFV vaccine Potency (Effective Dose end point-ED50)}

Potency of inactivated RVF viral vaccine candidates prepared using different chemical inactivants namely formalin, ascorbic acid and BPL was evaluated using mice immunization assay (MIA) [20-15]. The effective dose of vaccine that can protect $50 \%$ of infected mice was determined, where experimental vaccinal batches were 5 fold serially diluted (1/5-1/3125) using sterile HBSS, pH 7.2 \pm 2 , concentrated vaccine was included. Each dilution was inoculated intraperitoneally $(\mathrm{I} / \mathrm{P})$ as $0.3 \mathrm{ml}$ in 21 days old weaning mice, $14-16 \mathrm{gm}$ (10/dilution). Another set of 10 mice were left as negative control. One week later the $2^{\text {nd }}$ dose of the vaccine; diluted as previous was inoculated. 14 days post the 1 st shoot, a challenge dose of $0.1 \mathrm{ml}$ containing $1000-10000$ MIPLD $_{50}$ was intraperitoneally inoculated. Five weaning mice of the negative control group were challenged in the same way, the rest of control mice group were left as-negative control. Mortality was recorded throughout 14 days and the potency of inactivated RVF virus vaccines was determined [20].

\section{Preparation of Adjuvants}

Calcium phosphate nanoparticle adjuvant: Calcium phosphate nanoparticles was prepared by mixing Buffers $\mathrm{A}$ and $\mathrm{B}$, prepared by the rapid dissolution of $18.36 \mathrm{gm} \mathrm{Na} \mathrm{HPO}_{4}-12 \mathrm{H}_{2} \mathrm{O} ; 12.5 \mathrm{gm} \mathrm{NaOH}$; 
Citation: Abd el-Razek NEE, Shoman SA, Mohamed AF (2011) Nanocapsulated Rift Valley Fever Vaccine Candidates and Relative Immunological and Histopathological Reactivity in Out Bred Swiss Mice. J Vaccines Vaccin 2:115. doi:10.4172/2157-7560.1000115

$7.5 \mathrm{gm} \mathrm{NaHCO} 3$ in $325 \mathrm{ml}$ of distilled water and $10.75 \mathrm{gm} \mathrm{Ca}$ $\left(\mathrm{NO}_{3}\right)_{2} 4 \mathrm{H}_{2} \mathrm{O}$ in $125 \mathrm{ml}$ of distilled water. All buffers were sterilized by membrane filtration ( 0.022 Stereoscopy vacuum filtration system (Millipore -USA). Vaccines were homogenized in a $0.07 \mathrm{M}$ dibasic sodium phosphate sterile solution. The vaccine suspension was mixed with solution A prior to mixing to solution B. The precipitate of gel-like amorphous calcium phosphate formed was agitated for approximately 30 seconds. RVFV Vaccines becomes absorbed on the calcium phosphate nanoparticle adjuvant [29].

Aluminum phosphate (Alum) adjuvant: Both of $0.63 \mathrm{M}$ $\mathrm{AlCl}_{3} \cdot 6 \mathrm{H}_{2} \mathrm{O}$ and $0.3 \mathrm{M} \mathrm{Na}_{3} \mathrm{PO}_{4} \cdot 12 \mathrm{H}_{2} \mathrm{O}$ were prepared in $40 \mathrm{ml}$ normal saline each. Prepared solutions were $0.2 \mu \mathrm{m}$ filtered. Contents were stirred continuously during the procedure at 40 to $60 \mathrm{rpm} .0 .3 \mathrm{M}$ $\mathrm{Na}_{3} \mathrm{PO}_{4} \cdot 12 \mathrm{H}_{2} \mathrm{O}$ solution was added to a mixing bottle. $300 \mathrm{ml}$ normal saline was added. The antigen was added followed by addition of $0.63 \mathrm{M}$ $\mathrm{AlCl} 3.6 \mathrm{H}_{2} \mathrm{O}$ solution to the mixing bottle. $\mathrm{pH}$ was maintained between 6.5-6.8. The final volume was adjusted with sterile normal saline. The suspension was mixed for $2 \mathrm{hr}$ at $37^{\circ} \mathrm{C}$ [29-30].

Electron microscope scanning: The adjuvants were diluted with water until the solid content was $0.01 \%$. The copper grid was dipped into the suspension and allowed to air dry. Pictures were taken in a JEOL-JEM-1230 transmission electron microscope at a $\mathrm{x} 40,000$ magnification.

Immunization of experimental laboratory animals: Adjuvant formulated vaccines namely AA-RVFV, CAP-AA-RVFV, Alum-AARVFV, BPLRVFV, CAP-BPL-RVFV, Alum-BPL-RVFV, F-RVFV, CAPF-RVFV, Alum-F RVFV were used to immunize nine groups (10 / each) of Swiss weaning male mice (14-16 gm,) the immunizing dose $(0.5 \mathrm{ml})$ was administered subcutaneously $(\mathrm{S} / \mathrm{C})$. Another group was inoculated using PBS used as negative control.

Histopathological examinations: Three mice from each immunized and control groups were collected 24, $72 \mathrm{hrs}, 1,4$ and 8 weeks post immunization for cervical dislocation to get liver, kidney and spleen. The organs were $10 \%$ neutral-buffered formalin fixed and embedded in paraffin and prepared in the usual method. Sections were stained with haematoxylin and eosin (H-E) for histopathological examination [32].

Detection of antibodies against RVFV antigen: Blood samples were collected at 1 week interval through retro-orbital plexus of immunized mice. Sera were collected by cold centrifugation for 15 minutes at $5000 \mathrm{rpm}$. ELISA plates (Nunc - Denmark) were coated with RVF cell lysate Ag in carbonate-bicarbonate buffer, $\mathrm{pH} 9.6$ as $100 \mu \mathrm{l} /$ well. Plates were incubated for $18 \mathrm{hrs}$ at $+4 \mathrm{oC}$. Unattached $\mathrm{Ag}$ was washed out using wash buffer (PBS $-0.5 \%$ Tween 20 ). Sera samples were 2 fold serially diluted in the reciprocal wells plates were incubated for $2 \mathrm{hrs}$ at $37^{\circ} \mathrm{C}$. Plates were washed as previous to remove non reacting antibodies. Anti-mouse conjugate labelled with peroxidase enzyme (Sigma immuno-chemicals) was dispersed as $100 \mu \mathrm{l}$ as $1 / 1000$ final dilution. Plates were incubated for $1 \mathrm{hr}$ and unbound conjugate was washed. TMB substrate buffer (Sigma - Aldrich, USA) was added as $100 \mu \mathrm{l} /$ well. Plates were kept in dark for 20 minutes. The reaction was stopped using $100 \mu \mathrm{l}$ of $2 \mathrm{~N}$ hydrochloric acid $\mathrm{HCl}$ (Sigma -Aldrich, USA). Developed color was measured at $450 \mathrm{~nm}$ using ELISA reader (Tecan Sunrise - Austria), Ab level was blotted against weeks interval antibody level was evaluated [19].

\section{Statistical analysis}

Statistical analysis was performed using analysis of variance (one-way ANOVA), P value less than 0.05 was considered significant. Data collected from repeated experiments, Conducted at the same conditions but at different times, were pooled. All the results are presented as the difference between stimulated groups and the control groups. Comparisons among different groups were performed by oneway analysis of variance (ANOVA) Student $T$ test.

\section{Results}

\section{Toxicity of chemicals inactivates}

It was clear that $1.5 \mathrm{mg} / \mathrm{ml}$ of ascorbic acid, $0.2 \%$ of neutralized formalin and $0.0035 \mathrm{M}$ hydrolyzed BPL ( 2 hrs post preparation) were completely safe to tested mice behaved normally with no signs of illness and no mortality detected $24 \mathrm{hrs}$ and 7 days post administration.

\section{Inactivation of RVF virus using chemical inactivants}

Data recorded revealed that RVF virus was completely inactivated within $2 \mathrm{hrs}$, $6 \mathrm{hrs}$ and within $24 \mathrm{hrs}$ post treatment with $0.0035 \mathrm{M}$ BPL, $0.2 \%$ foirmalin and Ascorbic acid; recording a mean depletion of virus infectivity titre in the order of $1.2 \log _{(10)} / 15 \mathrm{~min}$ TCID50 and $1.8 \log _{(10)} / 15 \mathrm{~min}$ MIPLD50 (Figure 1), $1.2 \log _{(10)} / \mathrm{hr}$ TCID50 and 1.8 $\log _{(10)} / \mathrm{hr}$ MIPLD50 (Figure 2) and $0.95 \log _{(10)} / \mathrm{hr}$ TCID50 and 1.16 $\log _{(10)} /$ hr MIPLD50 respectively (Figure 3). Data revealed that BPL was significantly effective and faster as an inactivant than formalin and Ascorbic acid $(\mathrm{P}<0.05)$ and formalin was significantly short term effective than ascorbic acid $(\mathrm{P}<0.05)$.

\section{Determination of the inactivated Rift Valley fever (RVF) virus vaccine potency (ED50)}

Immune potential of prepared experimental Rift valley fever viral vaccine candidates (Vaccine potency; ED50) was evaluated according to [32]. The ED50 was contained in $0.006 \mathrm{ml}, 0.011 \mathrm{ml}$ and $0.0024 \mathrm{ml}$ of BPL, Formalin and Ascorbic acid vaccine respectively. That means that BPL was significantly higher than ascorbic acid and formalin respectively $(\mathrm{P}<0.05)$, (Table 1$)$.

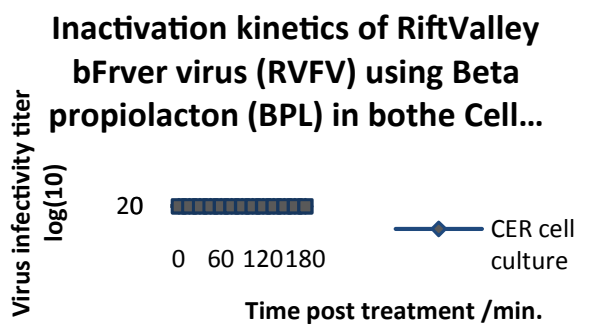

Figure 1: Evaluation of inactivation kinetics of Rift Valley Fever Virus using $0.0035 \mathrm{M}$ Beta-propiolactone in mice and cell culture.

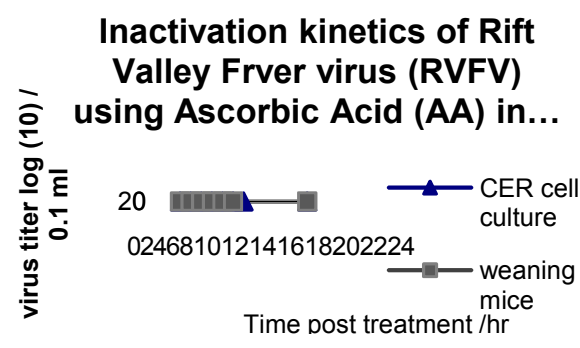

Figure 2: Evaluation of Inactivation Kinetics of Rift Valley Fever using ascorbicacid $1.5 \mathrm{mg} /$ final concentration in mice and cell culture. 
Citation: Abd el-Razek NEE, Shoman SA, Mohamed AF (2011) Nanocapsulated Rift Valley Fever Vaccine Candidates and Relative Immunological and Histopathological Reactivity in Out Bred Swiss Mice. J Vaccines Vaccin 2:115. doi:10.4172/2157-7560.1000115

Page 4 of 7

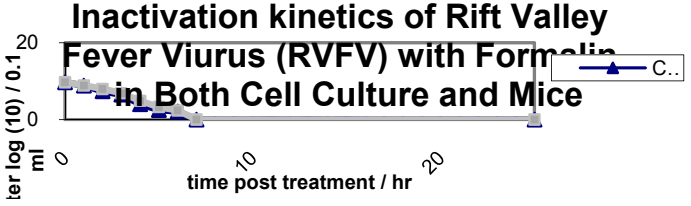

Figure 3: Evaluation of Inactivation Kinetics of RVFV using formalin in both mice and cell culture.

\begin{tabular}{|c|c|c|}
\hline Chemical Inactivant & $\mathrm{X}^{-}$potency (ED50) & $X^{-}$ED50 \\
\hline Ascorbic acid & $\begin{array}{l}0.0026 \\
0.0022\end{array}$ & 0.0024 \\
\hline Beta-propiolactone & $\begin{array}{l}0.007 \\
0.005\end{array}$ & 0.006 \\
\hline Formalin & $\begin{array}{l}0.01 \\
0.012\end{array}$ & 0.011 \\
\hline
\end{tabular}

Table 1: Determination of inactivated Rift Valley Fever virus vaccine Potency (ED50).

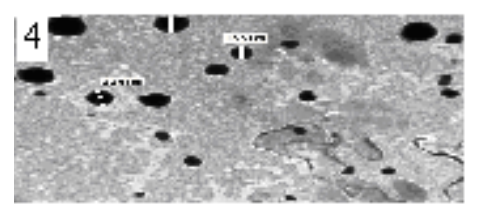

Figure 4: Transmission electron photomicrograph of $\mathrm{Abm}$ and calcium phosphate nanoparticle size. The barrepresents $0.5 \mu \mathrm{m}$.

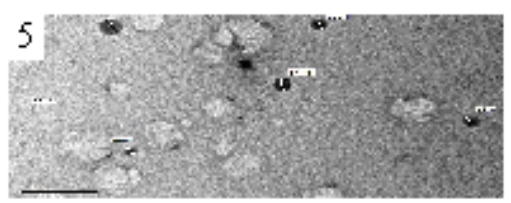

Figure 5: Transmission electron photomicrograph of $\mathrm{Abm}$ and calcium phosphate nanoparticle size. The barrepresents $0.5 \mu \mathrm{m}$.

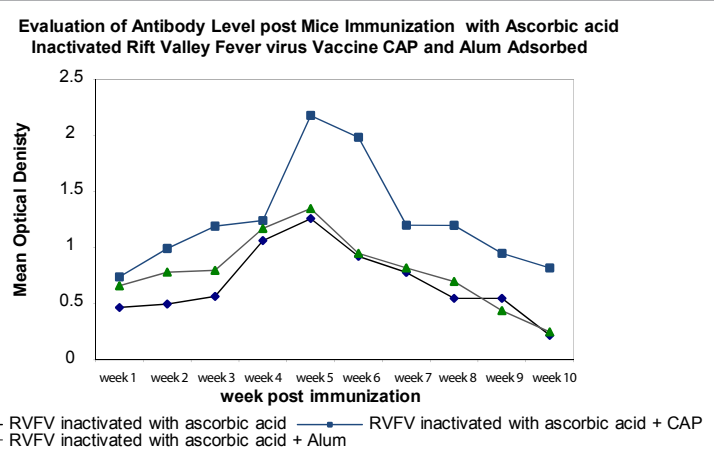

Figure 6: Evaluation of mice immune serum antibodies titre post immunization with ascorbic acid inactivated RVFV vaccines.

A transmission electron photomicrograph of aluminium phosphate adjuvant revealed that spherical particles of q mean particle size $\approx$ $208 \mathrm{~nm}$. Meanwhile, calcium phosphate nanoparticles were spherical particles and of a significantly reduced size $(\mathrm{P}<0.05)$ of $\approx 96 \mathrm{~nm}$ (Figure 4-5).

Evaluation of total antibody against RVFV vaccine in mice sera using ELISA

Immune reaction was enhanced due to the vaccine formulation using both Alum and CAP as adjuvants. Data recorded revealed that antibodies detected 7 days post immunization with Adjuvanted and non-adjuvanted vaccines. Data revealed that AA and Formalin non adjuvanted vaccines showed that they could induce a higher antibody level compared with antibody level detected post immunization with Beta propiolactone inactivated vaccine $(\mathrm{P}<0.05)$. Also, a significant elevated antibody level detected just throughout the1st 3 weeks followed by a nonsignifiicant change in case of AA-alum adjuvanted and non adjuvanted vaccine. On the contrary AA inactivated, CAP-Adjuvanted vaccine was highly significant immune stimulating vaccine than AAinactivated -Alum adjuvanted and non adjuvanted one $(\mathrm{P}>0.05)$, (Figure 6). In the mean time, Formalin inactivated vaccine Alum and CAP adjuvanted vaccines could enhance immune response despite there was a nonsignifiicant difference detected, and the superiority was to CAP -adjuvanted one than the other two types (Figure 8). Finally, BPL -CAP formulated vaccine showed a highly significant and long durative $\mathrm{Ab}$ level than that detected post immunization with BPL and $\mathrm{BPL}-$ Alum adjuvanted vaccines $(\mathrm{P}>0.05)$, (Figure 7 ).

\section{Histopathological studies}

Microscopic examination of mice Liver treated with calcium phosphate nanoparticle adjuvant $24 \mathrm{hr}$ revealed hydropic degeneration of hepatocytes (Figure 1), Moreover, after $72 \mathrm{hr}$, examined Liver showed multiple small focal areas of hepatic necrosis associated with leucocytic cells infiltration (Figure 2), Meanwhile, after 1 week later, Liver sections showed no changes except presence of small vacuoles in the cytoplasm of some hepatocytes (Figure 3). However, liver of mice after 4 weeks showed kupffer cells activation (Figure 4).Concerning Kidneys, examined sections of mice after $24 \mathrm{hr}$ showed congestion of intertubular blood capillaries (Figure 5). After 72 hr, Kidneys sections revealed focal renal haemorrhage (Figure 6), meanwhile, After 1 week

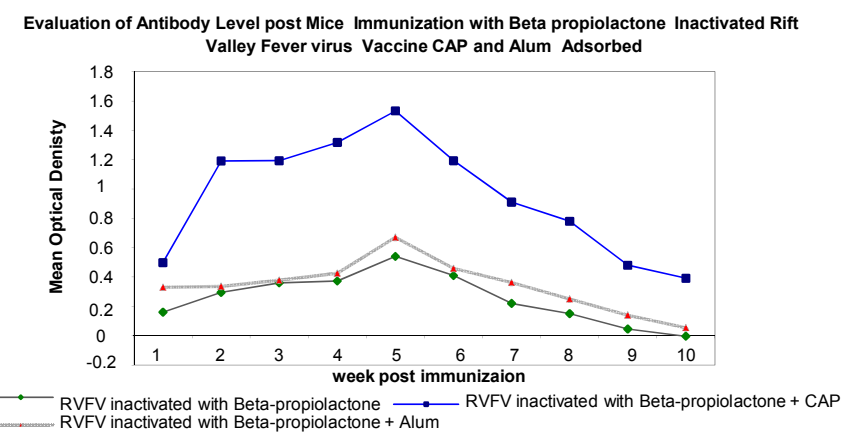

Figure 7: Evaluation of mice immune serum antibodies titre post immunization with Bpropiolactone inactivated RVFV vaccines.

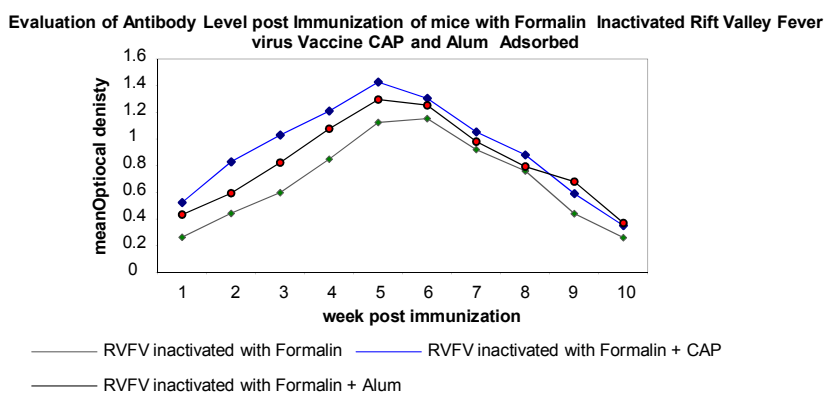

Figure 8: Evaluation of mice immune serum antibodies titre post immunization with formalin inactivated RVFV vaccines. 


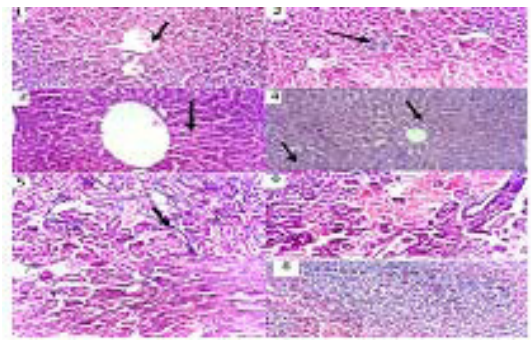

Figure 9:

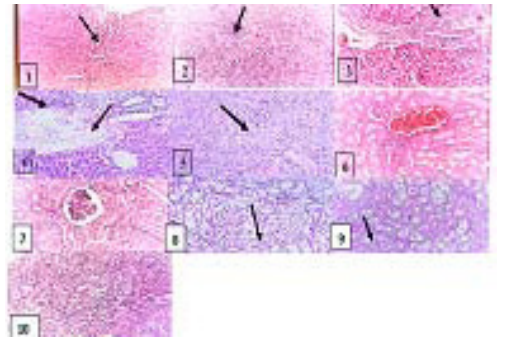

Figure 10:

and 4 weeks, examined Kidneys sections showed apparent normal renal parenchyma (Figure 7). Regarding Spleen, examined sections post treated with calcium phosphate nanoparticle adjuvant after $24 \mathrm{hr}, 72$ hr, 1 week and 4 weeks revealed no histopathological changes (Figure 8). Microscopically examination of mice Liver treated with aluminium phosphate adjuvant (alum) $24 \mathrm{hr}$ post immunization showed a portal infiltration with leukocytes (Figure1). Moreover, after $72 \mathrm{hr}$, examined Liver showed focal area of hepatic necrosis replaced by leucocytic cells infiltration (Figure 2), meanwhile, after 1 week, Liver sections showed massive leukocytic cells infiltration in the portal triad (Figure 3 ). Examined sections of Liver of mice after 4 weeks showed recent thrombus as well as portal infiltration with leucocytic inflammatory cells (Figure 4). At 8 weeks, liver of mice revealed small focal hepatic necrosis associated with leucocytic cells infiltration (Figure 5). Concerning Kidneys, examined sections after $24 \mathrm{hr}$ and $72 \mathrm{hr}$ showed congestion of renal blood vessel associated with focal leucocytic cells aggregation (Figure 6). After 1 week, Kidneys sections revealed thickening of the partial layer of Bowman's capsule (Figure 7). However, after 4 weeks, kidney of mice showing vaculation of epithelial lining renal tubules together with pykenosis of their nuclei (Figure 8), while at 8 weeks, showing cellular cast in the lumen of some renal tubules (Figure 9). Regarding Spleen, examined sections of mice treated with aluminium phosphate adjuvant after $24 \mathrm{hr}, 72 \mathrm{hr}, 1$ week, 4 week and 8 week showed similar changes described as lymphocytic depletion associated with appearance of multiple megakaryocytes (Figure 10).

\section{Discussion}

The present work aimed to improve the efficacy and reactogenicity of the current prepared RVFV vaccine in addition find alternative adjuvant can minimize the inflammatory reaction detected post the administration of Alum adjuvanted inactivated RVF virus vaccine. Rift valley fever virus vaccine prepared in Egypt since 1981[20-24]. The currently prepared vaccine is formalin inactivated one prepared in Abbassia Research institute for sera and veterinary vaccines and the Egyptian Organization for biological products and vaccines (VACSERA) despite the use of different strains; human (ZH-501) and sheep origin, M/S/258) respectively [2].The side effects of formaldehyde are well known and the risks are many. The use of new inactivants must be considered for availability, higher safety measures and better antigenicity. The choose of available, cheap and more safe inactivants are of the parameters for improving the quality and immunogenicity of the RVFV vaccines [22]. Ascorbic acid proved to has an antiviral activity to some viruses as Polio, rabies, cytomegalovirus viruses, in addition its effect on the released interferon level accordingly it was interestingly tried for the inactivation Rift Valley fever virus as an economic matter of importance [32]. Efficacy of inactivants was monitored and the inactivation kinetics was evaluated compared with formalin as the current and traditional inactivating agent. Meanwhile BPL was of the promising agent for vaccine production especially for human use as Rabies, Polio and influenza inactivated vaccines, as vaccine potency (ED50) varied according to the inactivating agents; BPL showed a higher vaccine potency than detected in case of using other inactivants, this was attributed to the limited effect on viral epitopes configuration to which the antigenicity is attributed, also it has no deleterious effect on the immune response as $\mathrm{CF}$ and $\mathrm{HI}$ antibody titre not affected post immunization, also, its concentration used for inactivation is a virus type dependent $[33,34]$, in turn an elevated immune potential is detected post immunization with BPL prepared vaccine compared with that elicited post immunization with formalin inactivated one [19]. Our recorded data was opposite to the recorded data by the others, Although the immune response detected pos immunization with CAP-non adjuvanted BPL inactivated vaccine the immune response was extremely enhanced post adjuvation to CAP nanoparticles and higher than the immune response detected in case of Alum Adjuvation. Also, immune response to AA-CAP and Alum adjuvanted RVFV vaccine candidates was in accordance to the same pattern of BPL adjuvanted vaccine but of as lower values. Data recorded revealed that the emergency to omit use of formalin as inactivant for its drawbacks and deficient immune enhancing and Alum are recommended. Neutralization of residual inactivants was known in case of formalin, where residual formalin is neutralized using 35\%Na-Bisulphite as $0.0218 \%$ [19,20,35] but not in case of A. Acid its mode of action on viral epitopes are unclear and it its mode of action mainly based on the oxidation reaction. Mean while, no way known to neutralize the residual A. Acid in prepared vaccines, in addition its stability in culture media is well known [36]. While, BPL is auto hydrolysed into propionic acid and water and its derivatives are safe, so why it is used in human vaccine production [25-37]. Concerning safety of chemical inactivants, it was a must, to assure the safety measure of prepared vaccine this was in accordance to [18-35]. Adjuvants have been necessary to improve vaccine efficacy in order to afford protection against infections. A key reason for this is that both attenuated virus preparations and, particularly, recombinant proteins are often poorly antigenic. In the past decade, several adjuvants have been evaluated in clinical trials. Calcium phosphate (CAP), MF59, aluminum (alum) compounds, and virosomes have been approved for human use in several European countries [7]. In the United States, alum compounds are the most extensively used adjuvants in licensed vaccines for humans and in Egypt as well. Although they effectively enhance immune responses, there are several disadvantages associated with their use $[6,8,9]$. The disadvantages of alum-based adjuvants include the severity of local tissue irritation, the longer duration of the inflammatory reaction at the injection site, strong Th2 responses, minimal induction of cellmediated immunity, and a propensity to elicit undesirable immunoglobulin $\mathrm{E}(\mathrm{IgE})$ responses $[10,12]$. Alum compounds have also been shown to increase the levels of potential undesirable homocytotropic antibodies in animal species [13]. Furthermore, alum-based vaccines are frequently ineffective for the induction of antiviral immunity [4] 
Citation: Abd el-Razek NEE, Shoman SA, Mohamed AF (2011) Nanocapsulated Rift Valley Fever Vaccine Candidates and Relative Immunological and Histopathological Reactivity in Out Bred Swiss Mice. J Vaccines Vaccin 2:115. doi:10.4172/2157-7560.1000115

Page 6 of 7

For these reasons, new adjuvants are being developed to enhance the immunity against weak antigens. New-generation adjuvants are designed to induce minimal side effects, enhance the duration of the immune response, and concurrently stimulate humoral, cellular, and mucosal immune responses. Furthermore, an ideal adjuvant would be biodegradable, economical, and simple to manufacture. In addition, it would have the potential to selectively trigger a defined class of immune response such as the T-helper 1 (Th1) CD41 T-cell response and cell-mediated immunity and have equal applicability for any newgeneration antigens. The over view of adjuvant explain why the addition of CAP was an advantage to improve RVFV vaccine candidates than that detected in case of using Alum, even immune response development was inactivating agents related. Data recorded was in accordance with $[15,19,41]$. Concerning the histopathological changes, data recorded revealed that cytotoxicity/histopathological changes post SC administration attributed to unknown explanation and it was a time dependent and adjuvant type related. Our data recorded was in accordance with [40]. Also, data recorded was on the contrary to [41] recorded that Clinical and toxicity evaluation indicated there is no irritation and inflammation on the experimented eyes compared with the control group by histological examination. Also, there is no toxic effect in the acute toxicology and allergic experiment. And based on their findings, they suggested that calcium phosphate nanoparticles may favour the localized ocular delivery of CAIs for the treatment of glaucoma. finally it can be concluded that CAP is a better immune response enhancer to RVFV veterinary vaccine in addition its safety is relative to fast degradability than alum in turn short term pathological changes followed by auto repair of toxified tissues. Also, combination of CAP with BPL followed by A. Acid inactivated vaccines was a better formulation than use of formalin and Alum adjuvanted vaccine.

\section{Acknowledgment}

The authors would like to thank Prof. Dr Ahmed Eid Fazary for revising manuscript, R\&D sector and cell culture staff for supplied materials and Dr Mohamed Rabie Chairman of VACSERA for availability of Facilities.

\section{References}

1. Lubroth J, Rweyemamu MM, Viljoen G, Diallo A, Dungu B, et al. (2007) Veterinary vaccines and their use in developing countries. Rev Sci Tech 26: 179-201.

2. WHO (2010) Safety and Immunogenicity Study of Rift Valley Fever Vaccine (RVF)

3. Gupta RK, Siber GR (1995) Adjuvants for human vaccine- current status, problems and feature prospects. Vaccine 13: 1263-1276.

4. Glenny AT, Pope CG, Waddington H, Wallace $U$ (1926) The antigenic value of toxoid precipitated by potassium alum. J Pathol Bacteriol 29: 38-45

5. Vogel FR, Powell MF (1995) A compendium of vaccine adjuvants and excipients. Pharm Biotechnol 6: 141-228.

6. Hem SL, White JL (1995) Structure and properties of aluminum-containing adjuvants. Pharm Biotechnol 6: 249-276.

7. He Q, Mitchell AR, Johnson SL, Wagner-Bartak C, Morcol T, et al. (2000). Calcium phosphate nanoparticle adjuvant. Clin Diagn Lab Immunol 7: 899-903.

8. Gupta RK (1998) Aluminum compounds as vaccine adjuvants. Adv Drug delivery rev 32: 155-172.

9. Wood RC, MacDonald KL, White KE, Hedberg CW, Hanson M, et al. (1993) Risk factors for lack of detectable antibody following hepatitis $B$ vaccination of Minnesota health care workers. JAMA 270: 2935-2939.

10. Confavreux C, Suissa A, Saddier P, Bourdes V, Vukusic S, et al. ( 2001) Vaccinations and the risk of relapse of multiple sclerosis. Vaccines in Multiple Sclerosis Group. N Engl J Med 344: 319-326.

11. Averhoff F, Mahoney F, Coleman P, Schatz G, Hurwitz E, et al. (1998) Immunogenicity of hepatitis $B$ vaccines: implications for persons at occupational risk of hepatitis B virus infection. Am J Prev Med 15: 1-8.
12. Yuen MF, Lim WL, Cheng CC, Lam SK, Lai CL (1999) Twelve-year follow-up of a prospective randomized trial of hepatitis $B$ recombinant DNA yeast vaccine versus plasma-derived vaccine without booster doses in children. Hepatology 29: 924-927.

13. Hadler S, Francis DP, Maynard JE (1986) Long-term immunogenicity and efficacy of hepatitis B vaccine in homosexual men. N Engl J Med 315: 209-214.

14. Zhang L, FX Gu, JM Chan, AZ Wang, RS Langer, et al. (2008) Nanoparticles in Medicine: Therapeutic Applications and Developments. Clinical pharmacology and therapeutics 83: 761-769.

15. He Q, Mitchell AR, Johnson SL, Wagner-Bartak C, Morcol T, et al. (2000) Calcium phosphate nanoparticle adjuvant. Clin Diagn Lab Immunol 7: 899-903.

16. Emerich DF, Thanos CG (2007) Targeted nanoparticle-based drug delivery and diagnosis. J Drug Target 15: 163-183.

17. Nikolai Petrovsky, Susanne Heinzel, Yoshikazu Honda, A. Bruce Lyons (2007) New-Age Vaccine Adjuvants: Friend or Foe? BioPharm International.

18. Aly FM, Mamoun AZ, Hekmat MT, Amal SM (2003) Comparative evaluation of different stability enhancer to liquid rabies vaccine at different thermal conditions. Egy Jour of Zoology 443-453.

19. Heba Ali, A El Gawad Hashem, O. El Tayeb, Aly Fahmy (2010) Evaluation of inactivation efficacy of Sabin Polio virus using different inactivating agents and its immunogenicity post nano and micro incapsulation. International journal of microbiological research 1: 114-122.

20. El-Karamany R, Imam I, Farid A (1981) Production of inactivated RVF vaccine. J Egypt Publ Health Assoc 56: 495-525.

21. Bussereau F, Benejean J, Saghi N (1982) Isolation and study of temperature sensitive mutants of rabies virus. GenVirol 60:153-158.

22. Madhusudana SN, Shamsundar R, Seetharaman S (2004) In Vitro inactivation of the rabies virus by ascorbic acid. Int $\mathrm{J}$ Infect Dis 8: 21-25.

23. Salo RJ, Cliver DO (1976) Effect of acid pH, salts, and temperature on the infectivity and physical integrity of enteroviruses. Arch Virol 52: 269-282.

24. El-Karamany RM (1987) Production in Vero cells of an inactivated rabies vaccine from strain FRV/K for animal and human use. Acta Virol 31: 321-328.

25. Reed LT, Muench HA (1938) simple method of calculating fty percent end point Am J Hyg 27: 493-498.

26. Ching FP, Omogbai EK, Ozolua RI, Okpo SO (2009): Analgesic activity of aqueous extract of stereospermum kunthianum (cham, sandrine petit) stem bark. Acta Pol Pharm 66: 83-88.

27. Ecobichon DJ (1997) The Basis of Toxiciology Testing. page 43, CRC Press, New York.

28. Salama LS (1991) Studies on the immune response of Rift valley fever vaccine. M Vsc Thesis Vet Med, Cairo University.

29. Gupta RK (1998) Aluminium compounds as vaccine adjuvants. Adv Drug Deliv Rev 32: 155-172.

30. Lindblad EB (1995) Aluminium adjuvants in theory and practical applicaton of adjuvants (Stewart-Tull, D.E.S., ed.), wiley, Chichester 21-35

31. John D. Bancraft, Marilyn Gamble (2002) Theory and Practice of Histological Techniques. Fifth Edition, Churchill Livingstone; London, Edinburgh, New York, Philadelphia, St. Louis, Sydney, Toronto.

32. Mohamed F.A.; El-Kaschef A.H.; Reda I.M; Tantawey HM, Hassen RA (1997) Biological studies for the importance of Rift Valley Fever Vaccine. ph.D thesis, Suez Canal Univ Zool Department.

33. Behbehani AM, McMillen JK, Hiller MS, Wenner HA (1967): Effect of ß-Propiolactone on Adventitious Viruses in mouse immune ascetic fluids and sera. Appl Microbiol 15: 940-942.

34. Blackburn NK, Besselaar TG (1991) A study of the effect of chemical inactivants on the epitopes of Rift Valley Fever virus glycoproteins using monoclonal antibodies. J Virol Methods 33: 367-374.

35. WHO (1983) The use of veterinary vaccine for prevention and control of Rift valley fever. Memorandom form W H O/FAD meeting. Bull World Health Organ 61: 261-268.

36. Cullen El, May V, Eipper BA (1986): Transport and stability of ascorbic acid in pituitary cultures. Mol Cell Endocrinol 48: 239-250. 
Citation: Abd el-Razek NEE, Shoman SA, Mohamed AF (2011) Nanocapsulated Rift Valley Fever Vaccine Candidates and Relative Immunological and Histopathological Reactivity in Out Bred Swiss Mice. J Vaccines Vaccin 2:115. doi:10.4172/2157-7560.1000115

37. WHO (1996) int/entity/rabies/vaccines/en/Laboratory_techniques_in_rabies_ chapter25.

38. Lazarowicz M, Kihm U, Bommeli W, Zutter R (1982) Potency testing of inactivated rabies vaccines in mice, dogs and cats. Comp Immunol Microbiol Infect Dis 5: 233-235.

39. Habib M, Hussain I, Irshad H, Yang ZZ, Shuai JB, et al. (2006) Immunogenicity of formaldehyde and binary ethylenimine inactivated infectious bursal disease virus in broiler chicks. J Zhejiang Univ Sci B 7: 660-664.

40. Patel GB, Zhou H, Ponce A, Chen W (2009) Safety Evaluation of Calcium Administered Intranasally to Mice. Int J Toxicol 28: 510-518.

41. Q He, Z Fang, M Wang, QW Xu, R Chen, et al. (2008) Lyceum Chinese and Calcium Phosphate Nanoparticles for Ophthalmic Drug Delivery. Nanotech 2: 401-404. 